\title{
Understanding Multilingual Young Adults and Adolescents' Digital literacies in the Wilds: Implications for Language and Literacy Classrooms
}

\author{
Yiting Han \\ National Institute of Education \\ Nanyang Technological University \\ Singapore
}

\begin{abstract}
Changes in digital landscapes have complex effects on the meaning-making that they mediate (Thorne et al., 2015). There is a growing interest in examining the daily digital literacy practices of today's multilingual young adults and adolescents, who are going to become the generation of future global communicators (Kim, 2016). Addressing current scholarship on multilingual digital literacy, this article examines 20 empirical studies on multilingual young adults and adolescents (ages 12-29) and their vernacular digital literacy practices beyond the classroom. Drawing upon multimodality and translanguaging perspectives that recognize literacy practices as ideological constructions produced within social contexts and across semiotic resources, the article identifies five emerging themes in research focusing on daily digital literacy practices of multilingual youths: recognizing cultural and linguistic diversity, exploring and constructing multifaceted identities online, leveraging technological affordances for communicating, gaining social support in virtual communities, and developing global citizenship through online intercultural exchanges. This article concludes with implications to support critical multilingualism and multimodality in language and literacy classrooms.
\end{abstract}

Keywords: multilingualism, multimodality, digital wilds, language and literacy, multilingual youth, digital literacy

Literacy is traditionally understood as meaning-making skills related to reading and writing. Digital communication has transformed literacy practices by expanding the ways of interpreting and making meaning in new spaces mediated by digital technologies (Gee, 2004; Reinhardt \& Thorne, 2011; Ware, 2017). The term "digital literacies" was created to describe internet- and technology-mediated literacies (Lankshear \& Knobel, 2008). As digital tools enhance the complexity and dynamics of meaning-making by enriching the semiotic resources available in the virtual world (Jewitt, 2009; Lotherington \& Jenson, 2011), digital literacies involve more than just reading and writing the text. Digital literacies encompass the decoding and encoding skills for any meaningful semiotic activity happening in digitally mediated environments, such as mobile apps, social media, and 
online games (Gee, 2004; Thorne, 2013). Semiotic resources are never neutral (Jewitt, 2009; Douglas Fir Group, 2016). They function as the "carriers of sociocultural patterns and knowledge" (Wertsch, 1994, p. 204). Thus, these new literacy practices in digital contexts are social practices in their very nature that involve the effective meaning-making and development of social roles in audience, community, and context-relevant ways (Gee, 2004; Thorne 2013).

Although access to the internet remains unequal in the world, technology-mediated activities have become ubiquitous (Mills, 2010). On the street, in public transport, at workplaces, people are connected to portable digital devices for various communicative needs across recreation, business, and academic sectors. Digital literacy practices have become an important part of life for approximately 4.3 billion people (Kemp, 2019). This is especially the case for adolescents and young adults. According to a 2018 social media use survey conducted by Pew Research Center, 93\% of adolescents aged 12 to 17 and $93 \%$ of young adults aged 18 to 29 engage with social media in the United States. This phenomenon has attracted growing attention. In New Literacy Studies (Barton \& Hamilton, 1998; Gee, 1996; Street, 2003), there is a shift toward research of digital literacy applications (Mills, 2010). Once exotic and underappreciated (Alvermann, 2008), digital literacies are becoming curricularized and even dominant in current pedagogical discourses (Lotherington \& Jenson, 2011; Sefton-Green et al., 2009). As educators integrate digital literacies into classrooms in meaningful ways (Beavis et al., 2014; Moje, 2016), there is a need to keep looking at the evolving online intercultural meaning-making practices in which youth are engaged for a more effective pedagogy that can better serve emergent bi/multilingual students. Therefore, a growing body of digital literacies related research was conducted in the "wild" (e.g., Black, 2009; Lam, 2000, 2004, 2009a), which means an informal digital context beyond the classroom. The term "in the wild" has been co-opted from cognitive science, referring to a natural, culturally based context outside of the laboratory (Hutchins, 1995). In linguacultural education, "wild" refers to socio-culturally based life contexts outside of classrooms. Building upon these concepts, the term "digital wilds" in this review was used to describe these outside-of-classroom, socio-cultural, context rich spaces mediated by digital technologies.

Many studies conducted in the digital wilds have shown that there are opportunities for learning in online informal communities (e.g., Black, 2005, 2009; Kim, 2016a; Kim, 2018; Lam, 2000, 2004). As digital technologies help connect people from various language and cultural backgrounds, this "intercultural interaction in the wild" (Thorne, 2010, p. 144), facilitated by technology, might contribute to the development of Communication, one of the important $21^{\text {st }}$ century skills ${ }^{1}$ that involves abilities to interact effectively with people from different cultures in a multilingual world. Communicating in a growing culturally and linguistically diverse world can be challenging. This review focuses on the generation of future global communicators - multilingual young adults and adolescents who are active multilingual communicators online. Understanding their meaningful digital literacy practices in real life might shed new and needed light on fostering important communication skills and advancing multilingual/multicultural education in this connected world.

\footnotetext{
${ }_{1}^{1}$ See http://www.p21.org/our-work/p21-framework
} 
As far back as 1956, Strevens pointed out the backbone of literacy and linguacultural education, stating that "one of two things must be done: either life must be brought to the classroom or the class must be taken to life" (Strevens, 1956, p. 69). Today, a growing body of research in new contexts continues to offer insights to bridge that gap (Buckingham, 2003). This review synthesizes and critically interprets the empirical research on multilingual adolescents and young adults' literacy practices in informal digitally mediated contexts. At a time when growing cultural and linguistic diversity at a global level is acknowledged and the importance of digital and multimodal forms of meaning-making is recognized (Kress, 2003; New London Group, 1996; Smith, 2014; Thorne, 2013), educators continue to explore the multimodal and multicultural digital literacies in which today's young people, the future global communicators, are engaged (e.g., Beavis et al., 2014; Knobel \& Lankshear, 2007). To better understand the empirical landscape of this growing field of research, this review investigates what has been done in the digital wilds through an inductive approach and offers recommendations to strengthen the links between daily digital literacies and linguacultural classrooms.

This article is divided into five sections. Following the theoretical discussion in the proceeding section, empirical studies addressing various aspects of digitally mediated language and literacy practices of multilingual young adults and adolescents were reviewed. The findings were thematically organized in the fourth section. The article concludes with a discussion of multilingual youths' vernacular digital literacies and implications for the research and teaching of language and literacy, and suggestions for future directions.

\section{Theoretical Frameworks}

Situated within New Literacy Studies (Barton \& Hamilton, 1998; Gee, 1996; Street 2003), multimodality (Kress, 2003, 2010; Kress \& van Leeuwen, 2001; Jewitt, 2009) and translanguaging (García \& Li, 2014; Li, 2011; Li \& García, 2016) offer us the conceptual lens to understand the new dynamics of meaning-making, mediated by digital tools in a globalized world. The two prominent frameworks recognize that literacy practices are ideological constructions produced within social contexts and that semiotic systems are involved in any act of literacy practice.

\section{Multimodality framework}

Rooted in social semiotics (Halliday, 1978; Hodge \& Kress, 1988), a multimodal framework is grounded in the understanding that meaning is constructed through the interweaving of a variety of modes, including but not limited to visuals, text, gestures, body movements and auditory modes (Kress, 2010). Multimodal communication is not new; as Kress (2010) puts it, multimodality is "the normal state of human communication" (p.1). Face to face communication involves a full array of non-verbal signs and books, and traditional literacy products have also used non-linguistic visual modes to accompany linguistic codes for centuries (Lotherington \& Jenson, 2011). Although multimodality does not only appear in digital contexts, digital tools intensify multimodal possibilities 
by expanding the ways and modes in which semiotic resources are intertwined and circulated in extended spaces mediated by digital technologies (Jewitt, 2009). Another important concept of a multimodal framework is that modes are socioculturally shaped and given meaning in different contexts. Literacy practices, including those happening in digital contexts, involve the construction of identity and community through the selection of modes and semiotic resources. Digital technologies, functioning as mediums, offer varying degrees of access to new online communities. Thus, new identities and social connections become available during meaning-making in digital spaces (Lam, 2000, 2004).

Utilizing a multimodal framework to investigate digital literacies, researchers recognize the multimodal nature of digital literacy practices and study them as dynamic social practices with a holistic understanding of contexts, interlocutors, modes, and symbolic systems. Researchers are showing how people use multiple modes and what choices they make mediated by the affordances of digital technologies (e.g., Chen, 2013; Kim, 2018). Furthermore, researchers guided by a multimodality framework might also ask the following questions: What identities are constructed through digital literacy practices? What communities are involved in meaning-making practices online?

\section{Translanguaging framework}

Translanguaging (García \& Li, 2014; Li, 2011; Li \& García, 2016) is an emerging framework to understand multilinguals' language use in a holistic sense. According to Li's (2011) definition, translanguaging is

both going between different linguistic structures and systems, including different modalities (speaking, writing, signing, listening, reading, remembering) and going beyond them. It includes the full range of linguistic performances of multilingual language users for purposes that transcend the combination of structures, the alternation between systems, the transmission of information and the representation of values, identities and relationships (p. 1223).

A translanguaging framework recognizes one's full linguistic system rather than a multilingual switch between separate language systems (García \& Kleyn, 2016). It goes beyond one language one identity (García \& Li, 2014), empowering individuals to explore and express identities through multiple literacy practices in more contextualized ways.

Critical to translanguaging is the idea that language and literacy practices are not fixed; they are dynamic, fluid, and under constant moment-to-moment negotiation. A growing body of studies on youth's digital literacy practices have also highlighted the fluidity of language and literacy practices, especially when individuals, especially transnationals, move across various digital communities (e.g., Kim, 2018; Lam, 2009a; McLean, 2010; Schreiber, 2015). Various digital platforms, including but not limited to social media, in- 
stant messaging, fanfiction sites and video-sharing sites, allow young people with multilingual backgrounds access and membership into semiotic rich virtual communities with a global audience. Such spaces allow for a flexible mix of languages and semiotic symbols. In addition, these platforms free multilinguals from pinpointing their identity to one single language and culture.

Researchers utilizing a translanguaging framework might be interested in multilingual young people's literacy practices in a world that is growing more multimodal and increasingly meditated by digital technologies. This framework helps us understand the fluidity, hybridity, and creativity of multilingual young people's digital literacy practices and how multilingual youths negotiate their relationships to and within the digitally mediated world.

\section{Methods of Review}

This review was guided by one central question: What are the key findings and predominant themes across the empirical research on multilingual young adults and adolescents' technologically mediated literacy practices?

\section{Study inclusion criteria}

This review focuses on multilingual young adults and adolescents' out-of-school digital literacy practices. Thus, studies that examined literacy practices of students (ages 1229) who were able to use more than one language in an out-of-classroom digitally mediated context were included in this review. Empirical studies published in peer-reviewed journals and books were eligible for inclusion. Non-empirical articles and studies that only focused on classroom-based digital literacy projects were excluded.

\section{Search process and analysis process}

Two strategies were utilized to locate potentially eligible studies. First, electronic searchers were conducted in the following academic databases: JSTOR, ERIC, Google Scholar and ProQuest. Keywords such as digital literacy, multilingual, multicultural, etc., were used to identify the studies. Second, peer-reviewed literacy, language learning, educational technology journals were manually reviewed (e.g., Language Learning and Technology, Learning, Media and Technology, Linguistics and Education, Journal of Adolescent \& Adult Literacy, Literacy, Reading Research Quarterly, and International Multilingual Research Journal). Given the scope of the review, articles that dealt with multilingual young people's digital literacy practices but did not provide empirical results were excluded. In total, 20 studies were found to meet the inclusion criteria, indicating that this area of research is still relatively new. The years of the studies range from 2000 to 2019.

My aim in examining these studies is to identify patterns and themes in the literature of multilingual young adults and adolescents' vernacular digital literacies. In the first step of the analysis, each study was read through. A spreadsheet noting research questions, research contexts (e.g., fandom, social media, etc.), participant's information (e.g., 
language learner, transnational youth, etc.), theoretical frameworks and summaries of studies was created. In the next step, key findings were identified (e.g., the L2 learners creatively employed English and Asian languages to enact cosmopolitan identities in online fanfiction sites) and compared across the corpus of the studies. I coded the findings for initial themes (e.g., multifaceted identities were constructed through digital literacy practices). In the final step, all studies were coded for each theme. The themes and their definitions were refined and distinguished during coding process. Illustrative examples were identified and color-coded in the spreadsheet.

\section{Findings}

A variety of research methods were utilized in the 20 studies that were selected for discussion, including case studies, virtual ethnographies and discourse analysis. The majority $(75 \%)$ of research on multilingual adolescents and young adults' informal digital literacies were presented as case studies, in which they usually focused on in-depth understandings of one to three individuals. Online publicly available data in virtual communities were also considered as valuable resources to study digital literacy practices in $20 \%$ of the studies. Most of the participants involved were multilingual speakers with a migration background (60\%). $40 \%$ of the participants are individuals learning a second language without experiencing migration (see Table 1).

In the following subsection, themes of findings across the studies on multilingual young adults and adolescents' informal digital literacies are synthesized and discussed. All the themes appear in order of prevalence.

Table 1. Summary of research design and participants of the selected literature $(n=20)$

\begin{tabular}{|c|c|c|}
\hline Characteristics & $\mathbf{n}$ & $\%$ \\
\hline \multicolumn{3}{|c|}{ Research Design } \\
\hline Case study & 15 & 75 \\
\hline Online content analysis & 4 & 20 \\
\hline Mix-methods & 1 & 5 \\
\hline \multicolumn{3}{|c|}{ Participants } \\
\hline Migration background & 12 & 60 \\
\hline $\begin{array}{l}\text { Language learner (no migration back- } \\
\text { ground) }\end{array}$ & 8 & 40 \\
\hline
\end{tabular}




\section{Theme One: Recognizing cultural and linguistic diversity}

All 20 studies reported on the role of multilingualism and multiculturalism in multilingual youths' informal digital literacy practices. In these studies, language and literacy practices were found to be multilingual and multicultural in their very nature. Their multilingual code choices were a creative remix of symbolic resources in their multilingual repertoire (Black, 2005, 2009; Chen, 2013; Domingo, 2012, 2014; Kim, 2018; Lam, 2009a; McGinnis et al., 2007; McLean, 2010; Schreiber, 2015). The freedom of manipulating linguistic, even non-linguistic codes in their multilingual, multicultural semiotic repertoire gives "all languages equal opportunities" (McLean, 2010, p. 18) and allows individuals to create new forms of literacy and cultural portfolios that traverse national borders (Kim, 2016a; Lam, 2006, 2009).

Such freedom offered by digital spaces illustrated that students were able to practice different languages (Black, 2009; Codreanu \& Combe, 2018; Lam, 2000, 2009b; Lam \& Rosario-Ramos, 2009). From the perspective of immigrant multilingual individuals, the navigation of online media allowed them to access linguistic resources of their country of origin to maintain and develop literacy in their heritage language (Lam, 2009b; Lam \& Rosario-Ramos, 2009). In her 2009 study focusing on two immigrant teenagers of Chinese origin, Lam described how these young people were using their heritage language as an intellectual tool to construct knowledge in a domain of interest in digital spaces. Similarly, Lam and Rosario-Ramos (2009) found that in digital spaces, thirty-five adolescents of diverse national origins in the U.S. used their 'home' languages to seek out information and political viewpoints from various sources. Their intentional use of heritage languages as a tool to construct knowledge and values not only helped them maintain and develop heritage language skills, but also sustain knowledge construction and personal learning journey through expanded access to news and ideas. From the perspective of language learners, online platforms and communities offered them opportunities to connect and interact with people around the world to develop their L2 skills (Black, 2009; Codreanu \& Combe, 2018). As described in Black's (2009) study on online fanfiction, three English language learners and active fanfiction writers were engaged in composing creatively across genres. They actively employed not only English, but also other Asian languages to collaborate with other youth online. In a recent study, Codreanu and Combe (2018) examined an L2 French learner's vlogs; this learner found that vlogs have the advantage of allowing him to speak and write with people around the world to practice his language skills and to practice his agency by expressing his opinions on languages and cultures. From these studies, we see that young people were given agency over their language use. Such agency allowed them to gain authorship in multiple languages to improve their language and literacy skills. Furthermore, the creative use of language facilitated new broader-crossing knowledge by remixing different cultures, histories, and experiences. 
The linguistic and cultural hybridity and diversity documented in these studies showed that multilingual young people's linguistic and cultural funds of knowledge were utilized to a greater extent. The acknowledgment of cultural and linguistic diversity outside of school walls empowers students to become agentive learners (Black, 2005, 2009) as well as to contribute to collective knowledge making in a more globalized world (Lam, 2009a, 2009b).

\section{Theme Two: Exploring and constructing multifaceted identities online}

The concept of identity was brought into focus in $90 \%$ of the studies. Research has shown how informal digital literacy practices facilitated the construction of multilayered identities for multilingual individuals to explore and negotiate who they are and their relationship to the world (Chen, 2013; Domingo, 2014; Kim, 2016a, 2016b; Lam, 2000, 2009a, 2009b; McLean, 2010; Schreiber, 2015). Some studies documented how multilingual young people with migration backgrounds used informal digital literacies to construct identities that distinguished them from monolingual peers (Lam, 2004, 2009a). In her 2004 study of two young Chinese immigrants in the U.S., Lam described how these two girls adopted a mixed code in a Chinese-English bilingual chatroom that distinguished them from monolingual English speakers and monolingual Cantonese speakers. Similarly, in 2009, Lam examined the instant messaging practices of an adolescent girl who had migrated from China to the U.S. and found that she used a range of linguistic and semiotic resources in constructing multiple affiliations across borders. A multilingual identity was maintained and developed through the use of multiple semiotic and communication tools.

Through varying degrees of access to new online communities, students were also able to negotiate new identities that helped them gain agency over their language use and learning (Black, 2009; Lam, 2000; McGinnis et al., 2007). For example, Lam (2000) explored online English practices of Almon, a youth who had emigrated from Hong Kong to the United States. Almon was frustrated by his English skills and felt marginalized in his English as Second Language classrooms. However, he was able to participate in an online interest group and negotiate a new identity as a global English user. Such new identity, and the agency it brought, allowed him to overcome the exclusion and marginalization that he often felt in formal classrooms. A study conducted in 2007 also found that multilingual youths used online spaces to gain social agency through voicing their opinions on political issues. McGinnis, Goodstein-Stolzenberg and Saliani documented three transnational young peoples' digital literacies and found that they asserted their voices in online public spaces on critical political issues that concerned them. Their identities were not confined to one single social system, which allowed them to gain agency over their language and literacy practices. These new identities, not only driven by socio-cultural contexts on digital platforms, but also motivated by language use and learning, illustrated a dynamic and multifaceted nature of identity practices empowered by digital literacies. 


\section{Theme Three: Leveraging technological affordances for commu- nicating}

During navigation across multiple languages, cultures, and identities, digital technologies were found to expand multilingual students' communicative competence and self-expression (Black, 2005, 2009; Chen, 2013; Codreanu \& Combe, 2018; Domingo, 2012, 2014; Kim, 2018; McGinnis et al., 2007; McLean, 2010; Schreiber, 2015). In order to achieve communicative needs, multilingual youths were able to leverage technological affordances (e.g., multiple modes and genres) to reach a broader audience (Codreanu \& Combe, 2018; Domingo, 2014; Schreiber, 2015), to achieve their rhetorical intent (Black, 2005, 2009) and to represent their affiliations and identifications (Chen, 2013; Kim, 2018; McGinnis et al., 2007; McLean, 2010).

Although it might be argued that a mixed linguistic code use limits the potential audience who share the same linguistic repertoire with multilingual individuals, a study of a Serbian multilingual university student who was also a rap artist found that multiple semiotic modes available on social media supported engagement of a variety of interlocutors regardless of their language proficiencies. In this study, Schreiber (2015) described how Aleksandar, the multilingual student, used videos and music to engage both non-English speakers in Serbian and non-Serbian speakers in the world. With the support of a variety of modes, language barriers, as he described, became relatively unimportant. Serving as a multimodal product sharing social networking site, YouTube was found to help multilingual young people communicate with a wide global audience (Codreanu \& Combe, 2018; Domingo, 2014). Online fanfiction sites were also found to support multilingual writers with multiple modalities to be read by a diverse audience (Black, 2005, 2009).

Along with reaching a broader audience, other modes of expression available online also allowed multilingual individuals to achieve rhetorical intent by augmenting words with other modes, such as images and sound (Black, 2005, 2009). In her 2005 virtual ethnographic study on Fanfiction.net, Black explored multilingual writers' fanfiction practices. She found that, through written texts, hyperlinks, anime videos, fan arts, etc., multilingual fanfiction writers expanded their writing and communication in online fan communities. These multimodal affordances not only helped multilingual writers with expression, but also provided them with more knowledge transferred from other genres with other modalities. In Black's (2009) fanfiction study, one of her participants, Nanako, created her fan product Crazy Love Letters to enact a plot from an anime series based on the movie You've Got Mail. Multiple media resources offered by the internet served as potential knowledge that they were able to draw on in the creation of their fan fiction texts.

Some studies also provided analysis on how multilingual youths represent their affiliations in online meaning-making through multimodal semiotic resources (Chen, 2013; Kim, 2018; McGinnis et al., 2007; McLean, 2010). For example, McLean (2010) examined the digital literacies of a 15-year-old Trinidad and Tobago native who had lived in the U.S. for four years. The youth integrated images and music that reference the national symbols, people, and culture of Trinidad and Tobago in her profile page to express her 
heritage and cultural identification. Similarly focusing on digital literacies and identity construction, Chen (2013) described how two Chinese international graduate students in the U.S. exploited the technological affordances of Facebook to communicate with a diverse audience. One of her participants, Jane, used a variety of modalities offered by Facebook, such as photos and hyperlinks of news about a Chinese female tennis player's performance to present a self-image of a proud Chinese citizen. These multimodal literacies, enriched by technological affordances, enabled social relations for wider communication.

\section{Theme Four: Gaining social support in virtual communities}

While the social nature of digital literacies is acknowledged (Gee, 2004; Reinhardt \& Thorne, 2011), so too is the importance of social support available in virtual communities (Black, 2005, 2009; Kim, 2016a, 2016b; Kim, 2018; Lam, 2000, 2003). When communicating in digital spaces, multilingual young people were likely to be involved in online affinity space (Gee, 2004), where they could develop a sense of belonging through connecting and communicating with people who share the same interests. Such sense of belonging nurtured young people's interests and motivated their self-directed learning (Kim, 2016a, 2016b). For example, Kim (2016a) conducted a discourse analysis in an online discussion forum about Korean dramas, focusing on participants without Korean heritage background. She found that a group of young people gathered in this online affinity space to support each other's interest in Korean dramas that was not well accepted in their local contexts. Their passion, engagement, and collective knowledge-making (e.g., discussing the dramas and making cultural comparisons) were maintained and appreciated instead of being marginalized. The possibilities for online affinity spaces to help overcome the exclusion and marginalization were also confirmed in Lam's (2000, 2003) studies. Almon, the transnational youth who was marginalized in ESL classrooms, was able to connect with online chat mates in a variety of places. Not only did he develop friendship with affinity group members, but he also became more confident about his life, career, and future.

Feedback from significant peers was found to be an important social support that multilingual youths gained from virtual communities (Black, 2005, 2009; Kim, 2016a, 2016b; $\mathrm{Kim}, 2018$ ). Such feedback supported the exploration of semiotic resources and composition (Black, 2005, 2009), the development of languages (Kim, 2016b; Kim, 2018), the exchange of linguacultural knowledge in the local and global contexts (Kim, 2016a, 2016b), and the creation of new knowledge remixing languages, cultures, and places (Black, 2005, 2009; Kim, 2016a, 2016b).

\section{Theme Five: Developing global citizenship through online inter- cultural exchanges}

Some research focused on the value of "intercultural interaction in the wild" (Thorne, 2010, p. 144) provided by digital spaces (Codreanu \& Combe, 2018; Hull et al., 2010; Kim, 2016a; Lam \& Rosario-Ramos, 2009; McGinnis et al., 2007). Both affordances and 
limitations were found in viewing international social networking sites as a place for multilingual young adults and adolescents to practice intercultural communication competence that would lead to the development of global citizenship.

Serving as a dynamic place where young people can share inquiries and knowledge about languages and cultures (Kim, 2016a, 2016b), digital spaces were found to help provoke fruitful conversations about cultures and improve cultural awareness. Kim (2016a) described how multilingual young people shared perspectives on their local cultural practices and interpretations of Korean cultural practices under a thread named "Alcohol in K-dramas?". These idea exchanges encouraged young people to think about and reflect on different cultural practices in both local and global contexts. By doing so, they could develop not only a cultural awareness about other cultures, but also an awareness of their home cultures.

Although being exposed to different perspectives helped raise cultural awareness, it was also noted that potentially harmful cultural discourses that occur online could prevent meaningful intercultural communication (Codreanu \& Combe, 2018; Kim, 2016a). For example, based on the analysis of YouTube comments triggered by an intercultural topic video created by an American L2 French learner, Codreanu and Combe (2018) found that although vlogs had the advantage of allowing learners to share cultural perspectives with people around the world, it did not always lead to a healthy and fruitful conversation. From some of the comments, they found that national and regional borders tended to persist in the minds of some viewers, and these could lead to extremely tense and harmful interactions.

Conversing interculturally in a digital world with unknown others requires skill, courage, empathy, and imagination (Hull et al., 2010); thus, it is very challenging for students. Focusing their research on multilingual young people's cosmopolitan practices in social networking sites, Hull, Stornaiuolo and Sahni (2010) categorized young people's intercultural digital literacy practices into two broad types: "everyday cosmopolitanism" (micro-moments of online intercultural exchange) and "intercultural triggers" (triggers that lead to noticeable shifts in attitudes and actions). The dynamic aspects of intercultural digital literacies were highlighted in their study because even everyday cosmopolitan practices, such as extending simple greetings, were not always smooth as youths' different cultural backgrounds intermingled. Intercultural triggers were emergent and unpredictable, distributed across the interlocutors, the activities, and the artifacts. On the one hand, these researchers acknowledged the value of social networking sites functioning as sites of intercultural and cosmopolitan practices. On the other hand, they suggested that teachers should provide scaffolding via offline conversations about culture, identity, and communication in local and global contexts to assist their learners' development of a sense of global citizenship. 


\section{Discussion}

The goal of this review was to synthesize empirical studies on multilingual young adults and adolescents' digital literacy practices in order to understand the what, the how and the why, and to rethink how we respond to these practices and findings as educators and researchers. Because it is still a relatively new area of study, 20 studies ranging from 2000 to 2019 were collected and analyzed. Five main themes emerged to help us tackle the what, the how, and the why of digital literacy and language education. Together, these studies illustrated the current landscape and raised both question marks and exclamation points for researchers and practitioners.

Research on multilingual young adults' and adolescents' out-of-school digital literacies revealed that these young people navigate across multiple languages, cultures, semiotic resources, and identities through their literacy practices. Their communicative needs are supported and expanded by technological affordances, enabling development of meaningful social connections. Negotiating and sharing ideas with people from a variety of places prepares students to become engaged citizens in a connected world. These findings also revealed possibilities of bridging the gap between learning in the classroom and learning in the digital wilds for a variety of reasons, including meeting the needs of today's multilingual youths, empowering agency, and making schooling more relevant in the digital age.

Hybridity and creativity are salient features of these literacy practices in the digital wilds (Moje, 2016). An innovative blending of multiple languages, cultures, and symbolic resources challenges the traditional language ideology that relies on national and ethnic boundaries, dividing language users into hierarchical power-unbalanced groups as native speakers and non-native speakers. These concepts were grounded in flat literacies and we are beginning to challenge these discourses in literacy and language classrooms (Pacheco \& Smith, 2015; Warner \& Dupuy, 2018). Therefore, there is a growing call to appreciate linguistically and culturally diverse students' communicative repertoires for learning and knowledge-making. Unfortunately, some multilingual youth, especially transnational youth, were kept invisible or marginalized in formal classrooms (Lam, 2000, 2003), or even considered as "at-risk" students, struggling in academic sittings (Domingo, 2012). In many cases, certain online communities, especially affinity spaces, did not acknowledge the national or ethnic boundaries that categorize languages into specific speech groups, marking insiders and outsiders based on nationality, race, and language proficiency. Such openness allows multilingual youth to draw on multilingual, multicultural experiences and perspectives to empower themselves to regain agency over their learning and lives (Lam, 2000) and to contribute to global collective knowledge-making (Kim, 2016a, 2016b). As multilingual code should be recognized as the 21st century's language for communication, so should this creative hybridization of semiotic resources, known as multimodal codemeshing (Pacheco \& Smith, 2015), be supported as a legitimate mode of communication. Multimodal codemeshing allows students to maximize creativity by expanding access to expression of meanings; it allows them to explore 
themselves and the world by navigating across semiotic repertoires. Products of this kind are now finding their ways into school classrooms (Hafner, 2014, 2015). Students in classrooms where multiple languages are spoken should be encouraged to draw on multilingual and multimodal semiotic repertoire to critically engage in personally and socially significant issues.

The social nature of these informal digital literacies was emphasized again in the current studies. Research has revealed how these literacy practices were enacted to exercise identities and agency, to facilitate collaboration, and to build meaningful social connections. These findings remind us of the core concept of literacy as social practices of communication, relationship building, and identity work. Many young people today might find their own definition of being literate (Alvermann, 2008). What they have learned from navigating the multilingual and multicultural internet might compete with how their school defines "being literate." This indicates a need to challenge our dichotomous thinking of formal versus informal learning and initiates a call to address the relationship between the acquisition of academic knowledge and life-wide identity-related needs.

With a few clicks of a mouse, young people can enter a world where the distinctions of producer/consumer are blurred, where the ways to access, process, and present information have been changed and expanded, and where learning occurs within a larger linguistic, social, and cultural network. These findings are exciting, though they raise important questions around integrating technologies into language and literacy classrooms. For example, what technologies should we use? How can we deal with inequalities for access? What difficulties will teachers face? How will these multimodal products be assessed to capture its richness?

These findings also lead educators to rethink the goal of literacy education. As Lam and Kramsch (2003) argue, our goal is to prepare students for "workplace and civic involvement" (p.13). Based on the findings of this review, online literacy practices allow young multilingual users to practice languages in rich contexts, to take agency over their learning, to explore and construct multiple identities, and to foster intercultural communication skills and a sense of global citizenship. These advantages brought by online literacies may help prepare students to become engaged social members in the global and the local contexts through open dialogues. As classroom pedagogies continue shifting the narrative from developing test takers to nurturing agentive social members, researchers and practitioners can learn from students' vernacular digital literacies in which they engage to explore and explain the changing world. Although the literature has shown positive outcomes, it is important to take into consideration the negative aspects of vernacular digital literacy (e.g., harmful online interactions) as educators integrate them into classrooms 


\section{Implications}

These challenges, along with new possibilities, make apparent some actions we need to take as educators and researchers. Language and literacy curricula, in considering the learning requirements of students who would become communicators and citizens of the globalized world, should explicitly address the kinds of practices, contexts, texts, modes, symbol systems, and interlocutors that position young people so that they can become more aware of and engaged in the global and the local contexts. Teachers need to help students critically reflect on the social roles and relations that they are constructing through their literacy practices in digital spaces; for example, teachers can guide how they select, shift, and remix codes, registers, and styles (Darvin \& Norton, 2015) for different social purposes and in different contexts. Educators should reconsider the significance of identity development in the process of language and literacy learning to better assist students to engage their life practices and purposes by designing identity-related storytelling or problem-solving projects (Pacheco \& Smith, 2015). It would also be beneficial for educators to have an explicit discussion or reflection with students on their identity development and digital meaning-making.

A paradigm shift from print-based curriculum to multiliteracies for literacy and language arts classrooms has emerged in recent years (Warner \& Dupuy, 2018). Moving forward, students should be allowed to work in the multicultural contact zones, with multilingual and multimodal semiotic repertoires. Multiple languages, cultural voices, and identities can be included through the use of various digital tools to bring their informal digital literacy practices to literacy classrooms. This effort can be accomplished with integration of bridging activities (Thorne \& Reinhardt, 2008), including "observation and collection, guided exploration and analysis, and creation and participation" (p.566) that extend students' vernacular literacies to increase student agency and to raise student awareness of desired social-communicative outcomes and symbolic values in different socio-cultural contexts. By navigating between vernacular and formal genres, students can access their funds of multilingual knowledge and develop a high level of audience and context awareness. Last but not least, students can become aware of possibilities for gaining support from online affinity spaces.

Due to the richness and fluidity of literacy practices in the digital wilds, more studies could focus on digital spaces as a research site to gain more insight into the dynamic aspects of global young people's meaning-making, not only on a micro scale, but also the macro scale that is shaping the landscape of the digital wilds. More longitudinal studies that focus on an individual's trajectory across virtual spaces and time could shed some light on a holistic understanding of a learning journey that develops over time and space. When linking the digital wilds with today's classrooms, researchers also need to further explore the effectiveness or tension which arises when teachers implement online informal multilingual digital literacies in a formal classroom setting around the world. Some studies provide insights for less studied contexts, such as high-poverty environments (see Comber, 2014). It would also be beneficial for more research to investigate informal multilingual digital literacy through a lens of critical social practices and critical 
media literacy (Alvermann et al., 1999). In a multilingual world, people consume media across different languages, cultures, and societies. These meaning-making practices are contextualized, mediated, and circumscribed by different inequalities. Adopting a critical media literacy lens could improve young multilingual users' critical thinking and intercultural competencies, which are essential skills in the 21 st century.

\section{Conclusion}

This review synthesizes and critically interprets the empirical research on vernacular digital literacy practices of multilingual young adults and adolescents (ages 12-29) beyond the classroom. Qualitative coding revealed five main themes on what has been learned thus far. Sequenced according to prevalence, research has found that through vernacular digital literacy practices, multilingual youths were able to: 1) utilize their linguistic and cultural funds of knowledge to a greater extent; 2) negotiate dynamic and multifaceted identities; 3) leverage technological affordances for wider communication; 4) gain social support in virtual communities; and 5) practice intercultural communication competence that would lead to the development of global citizenship. Hopefully, the findings of this review provide insights into the potential of meaningful vernacular digital literacy practices to empower today's multilingual youths to navigate the world they live in and make meanings through multimodal ensembles. There is still much to be learned as we work to meaningfully integrate digital literacies into literacy and language classrooms and empower students to become agentive, critical, and responsible social beings in the technological age. 


\section{References}

Alvermann, D. E. (2008). Why bother theorizing adolescents' online literacies for classroom practice and research? Journal of Adolescent \& Adult Literacy, 52(1), 8-19. https://www.jstor.org/stable/30139646

Alvermann, D. E., Moon, J. S., Hagwood, M. C., \& Hagood, M. C. (1999). Popular culture in the classroom: Teaching and researching critical media literacy. Newark, DE: International Reading Association.

Barton, D., \& Hamilton, M. (1998). Local literacies: Reading and writing in one community. London: Routledge.

Beavis, C., Rowan, L., Dezuanni, M., McGillivray, C., O’Mara, J., Prestridge, S., \& Zagami, J. (2014). Teachers' beliefs about the possibilities and limitations of digital games in classrooms. E-learning and Digital Media, 11(6). https://doi. org/10.2304/elea.2014.11.6.569

Black, R. W. (2005). Access and affiliation: The literacy and composition practices of English-language learners in an online fanfiction community. Journal of Adolescent \& Adult Literacy, 49(2), 118-128. https://www.jstor.org/ stable/40017563

Black, R. W. (2009). Online Fanfiction, global identities, and imagination. Research in the Teaching of English, 43(4), 397-425. https://www.jstor.org/stable/27784341

Buckingham, D. (2003). Media education: literacy, learning and contemporary culture. Cambridge, UK: Polity Press.

Chen, H. I. (2013). Identity practices of multilingual writers in social networking spaces. Language Learning \& Technology, 17(2), 143-170. http://dx.doi.org/10125/44328

Codreanu, T., \& Combe, C. (2018). Glocal tensions: Exploring the dynamics of intercultural communication through a language learner's vlog. In R. Kern \& C. Develotte (Eds.), Screens and scenes: Multimodal communication in online intercultural encounters (pp. 40-61). New York, NY: Routledge.

Comber, B. (2014). Literacy, poverty and schooling: What matters in young people's education? Literacy, 48(3), 115-123. https://doi.org/10.1111/lit.12041

Darvin, R., \& Norton, B. (2015). Identity and a model of investment in Applied Linguistics. Annual Review of Applied Linguistics, 35, 36-56. https://doi. org/10.1017/S0267190514000191

Domingo, M. (2012). Linguistic layering: Social language development in the context of multimodal design and digital technologies. Learning, Media \& Technology, 37(2), 177-197. https://doi.org/10.1080/17439884.2012.670645 
Domingo, M. (2014). Transnational language flows in digital platforms: A study of urban youth and their multimodal text making. Pedagogies: An International Journal, 9(1), 7-25. https://doi.org/10.1080/1554480X.2013.877554

Douglas Fir Group. (2016). A transdisciplinary framework for SLA in a multilingual world. Modern Language Journal, 100 (Supplement 2016), 19-47. https://doi. org/10.1111/modl.12301

García, O., \& Kleyn, T. (Eds.). (2016). Translanguaging with multilingual students: Learning from classroom moments. New York, NY: Routledge.

García, O., \& Li, W. (2014). Translanguaging: Language, bilingualism and education. Basingstoke, UK: Palgrave Macmillan.

Gee, J. P. (1996). Social linguistics and literacies: Ideology in discourses (2nd ed.). New York: Routledge and Falmer.

Gee, J. P. (2004). Situated language and learning: A critique of traditional schooling. London: Routledge.

Hafner, C. A. (2014). Embedding digital literacies in English language teaching: Students' digital video projects as multimodal ensembles. TESOL Quarterly, 48(4), 655-685. https://doi.org/10.1002/tesq.138

Hafner, C. A. (2015). Remix culture and English language teaching: The expression of learner voice in digital multimodal compositions. TESOL Quarterly, 49(3), 486509. https://doi.org/10.1002/tesq.238

Halliday, M. A. K. (1978). Language as social semiotic: The social interpretation of language and meaning. London, UK: Edward Arnold.

Hodge, R., \& Kress, G. (1988). Social semiotics. Cambridge, UK: Polity Press.

Hull, G. A., Stornaiuolo, A., \& Sahni, U. (2010). Cultural citizenship and cosmopolitan practice: Global youth communicate online. English Education, 42(4), 331-367. https://www.jstor.org/stable/23018017

Hutchins, E. (1995). Cognition in the Wild. Cambridge, UK: MIT Press.

Jewitt, C. (2009). The Routledge Handbook of Multimodal Analysis. London: Routledge.

Kemp, S. (2019, January 31). Digital 2019: Global digital overview. Datareportal. https://datareportal.com/reports/digital-2019-global-digital-overview

Kim, G. M. (2016a). Transcultural digital literacies: Cross-border connections and selfrepresentations in an online forum. Reading Research Quarterly, 51(2), 199-219. https://doi.org/10.1002/rrq.131 
Kim, G. M. (2016b). Practicing multilingual identities: Online interactions in a Korean dramas forum. International Multilingual Research Journal, 10(4), 254-272. https://doi.org/10.1080/19313152.2016.1192849

Kim, S. (2018). "It was kind of a given that we were all multilingual": Transnational youth identity work in digital translanguaging. Linguistics and Education, 43, 39-52. https://doi.org/10.1016/j.linged.2017.10.008

Knobel, M., \& Lankshear, C. (2007). Online memes, affinities and cultural production. In M. Knobel \& C. Lankshear (Eds.), A new literacies sampler (pp. 199-228). New York: Peter Lang Publishing.

Kress, G. (2003). Literacy in the new media age. London: Routledge.

Kress, G. (2010). Multimodality: A social semiotic approach to contemporary communication. New York: Routledge.

Kress, G., \& Van Leeuwen, T. (2001). Multimodal discourse: The modes and media of contemporary communication. London: Edward Arnold.

Lam, W. S. E. (2000). Literacy and the design of the self: A case study of a teenager writing on the Internet. TESOL Quarterly, 34, 457-482. https://doi. org/10.2307/3587739

Lam, W. S. E. (2004). Second language socialization in a bilingual chat room: Global and local considerations. Language Learning \& Technology, 8, 44-65.

Lam, W. S. E. (2006). Re-envisioning language, literacy, and the immigrant subject in new mediascapes. Pedagogies: An International Journal, 1(3), 171-195. DOI:10.1207/s15544818ped0103_2

Lam, W. S. E. (2009a). Multiliteracies on instant messaging in negotiating local, translocal, and transnational affiliations: A case of an adolescent immigrant. Reading Research Quarterly,44(4), 377-397. http://dx.doi. org/10.1598/RRQ.44.4.5

Lam, W. S. E. (2009b). Literacy and learning across transnational online spaces. E-Learning and Digital Media, 6(4), 303-324. https://doi.org/10.2304/ elea.2009.6.4.303

Lam, W. S. E., \& Rosario-Ramos, E. (2009). Multilingual literacies in transnational digitally mediated contexts: An exploratory study of immigrant teens in the United States. Language and Education, 23(2), 171-190. https://doi. org/10.1080/09500780802152929 
Lam, W. S. E. \& Kramsch, C. (2003). The ecology of an SLA community in computermediated environments. In J. H. Leather \& J. van Dam (Eds.), Ecology of Language Acquisition (pp.141-158). Dordrecht, The Netherlands: Kluwer Publishers.

Lankshear, C., \& Knobel, M. (2008). Digital literacies: Concepts, policies and practices. New York: Peter Lang.

Li, W. (2011). Moment analysis and translanguaging space: Discursive construction of identities by multilingual Chinese youth in Britain. Journal of Pragmatics, 43(5),1222-1235. https://doi.org/10.1016/j.pragma.2010.07.035

Li, W., \& García, O. (2016). From researching translanguaging to translanguaging research. In K. King \& Y. Lai (Eds.), Research Methods. In Encyclopedia of Language and Education (pp. 1-14). Springer.

Lotherington, H., \& Jenson, J. (2011). Teaching multimodal and digital literacy in L2 settings: New literacies, new basics, new pedagogies. Annual Review of Applied Linguistics, 31, 226-246. DOI: 10.1017/S0267190511000110

McGinnis, T., Goodstein-Stolzenberg, A., \& Saliani, E.C. (2007). "Indnpride": Online spaces of transnational youth as sites of creative and sophisticated literacy and identity work. Linguistics and Education, 18(3/4), 283-304. https://doi. org/10.1016/j.linged.2007.07.006

McLean, C.A. (2010). A space called home: An immigrant adolescent's digital literacy practices. Journal of Adolescent \& Adult Literacy, 54(1), 13-22. https://doi. org/10.1598/JAAL.54.1.2

Mills, K. A. (2010). A review of the "digital turn" in the new literacy studies. Review of Educational Research, 80(2), 246-271. https://doi. org/10.3102/0034654310364401

Moje, E. B. (2016). Youth literacy and cultural theories: A review of the science and implications for policy. Policy Insights from the Behavioral and Brain Sciences, 3(1), 70-76. https://doi.org/10.1177/2372732215624709

New London Group. (1996). A pedagogy of multiliteracies: Designing social futures. Harvard Educational Review, 66, 60-92.

Pacheco, M. B., \& Smith, B. E. (2015). Across languages, modes, and identities: Bilingual adolescents' multimodal codemeshing in the literacy classroom. Bilingual Research Journal, 38(3), 292-312. https://doi.org/10.1080/15235882.20 15.1091051

Reinhardt, J., \& Thorne, S. L. (2011). Beyond comparisons: Frameworks for developing digital L2 literacies. In N. Arnold \& L. Ducate (Eds.), Present and future promises 
of call:From theory and research to new directions in language teaching (pp. 257-280). San Marcos, TX: CALICO.

Schreiber, B. R. (2015). 'I Am What I Am': Multilingual identity and digital translanguaging. Language Learning \& Technology, 19(3), 69-87. http://dx.doi.org/10125/44434

Sefton-Green, J., Nixon, H., \& Erstad, O. (2009). Reviewing approaches and perspectives on "digital literacy". Pedagogies: An International Journal, 4(2), 107-125.

Smith, B. E. (2014). Beyond words: A review of research on adolescents and multimodal composition. In R. E. Ferdig \& K. E. Pytash (Eds.). Exploring multimodal composition and digital writing (pp. 1-19). Hershey, PA: IGI Global.

Street, B. (2003). What's "new" in the new literacy studies? Critical approaches to literacy in theory and practice. Current Issues in Comparative Education, 5(2), 77-91.

Strevens, P. (1956) Spoken language: an introduction for teachers and students in Africa. London: Longmans, Green and Co.

Thorne, S. L. (2010). The 'Intercultural Turn' and language learning in the crucible of new media. In F. Helm \& S. Guth (Eds.), Telecollaboration 2.0 for Language and Intercultural Learning (pp. 139-164). Bern: Peter Lang.

Thorne, S. L. (2013). Digital Literacies. In M. Hawkins (Ed.), Framing languages and literacies: Socially situated views and perspectives (pp. 192-218). New York: Routledge.

Thorne, S. L., \& Reinhardt, J. (2008). Bridging Activities. CALICO, 25(3), 558-572.

Thorne, S. L., Sauro, S., \& Smith, B. (2015). Technologies, identities, and expressive activity. Annual Review of Applied Linguistics, 35, 215-233. https://doi.org/10.1017/S0267190514000257

Ware, P. (2017). Technology, new literacies, and language learners. In C. Chapelle \& S. Sauro (Eds.), The handbook of technology and second language teaching and learning (pp. 265-277). Hoboken, NJ: John Wiley \& Sons, Inc.

Warner, C., \& Dupuy, B. (2018). Moving toward multiliteracies in foreign language teaching: Past and present perspectives... and beyond. Foreign Language Annals, 51(1), 116-128. https://doi.org/10.1111/flan.12316

Wertsch, J. V. (1994). The primacy of mediated action in sociocultural studies. Mind, Culture, and Activity, 1(4), 202-208. DOI: 10.1080/10749039409524672 